\title{
Assessment of Inventory Management Practices at the Ethiopian Pharmaceuticals Supply Agency, Addis Ababa, Ethiopia
}

This article was published in the following Dove Press journal: Integrated Pharmacy Research and Practice

\section{Bekele Boche \\ Tidenek Mulugeta (D) \\ Tadesse Gudeta (D)}

Department of Social and Administrative Pharmacy, School of Pharmacy, Faculty of Health Sciences, Jimma University, Jimma, Oromia, Ethiopia
Correspondence: Tidenek Mulugeta Email tidenekII@gmail.com
Background: Maintaining an adequate level of inventory is critical since an enormous amount of capital tied up with it. Having excess inventory leads to wastage. On the contrary, insufficient commodity leads to stock out. Hence, this study aimed to assess inventory management practices of program commodities at Ethiopian Pharmaceutical Supply Agency.

Methods: A descriptive cross-sectional study complemented with a qualitative method was conducted from February 21 to April 20/2019. Order fill rate, wastage rate, frequency of emergency order, acceptable storage condition met, and stock out were the metrics we used to measure the inventory management practices of the agency. Quantitative data were collected through physical observation of the warehouses and review of logistics management tools. Seventeen in-depth interviews were conducted to explore the challenges of inventory management.

Results: From the total 70 program commodities managed by the agency, $2.1 \%$ wasted due to expiration and damage. These resulted in a loss of over US \$2 million. The highest wastage was recorded for antimalarials which accounted for $13.1 \%$ of the malaria commodities' total inventory value. Only $14.8 \%$ of the orders were fulfilled above $80 \%$. Thirty-seven items were stock out on average for 8.5 average days. Longer duration of stock out (260 days) was recorded for TB commodities. Seventeen items from different programs were purchased through emergency orders with a higher frequency of levonorgestrel purchase. Only $6(60 \%)$ warehouses met acceptable storage conditions. Space deficit, outdated warehouse designs, shortage of warehouse equipment, lack of precise data, and capacity building gaps were the inventory management challenges identified.

Conclusion: Though the wastage rate was near to the acceptable range, there were lesser order fill rates, storage condition inadequacy, and significant stock-outs of program commodities. The finding implies the need for an improvement in inventory management practice of the agency.

Keywords: program commodities, EPSA, inventory management

\section{Background}

Pharmaceutical inventory management is about planning and controlling inventory levels to meet customer demand. Maintaining an adequate level of inventory is critical since an enormous amount of capital tied up with it. Having excess inventory leads to wastage of resources. Pharmaceutical stock loses its utility beyond some specified period. So, carrying over stock opens up the chance of losing thousands of dollars on expired, unsaleable items. Once pharmaceuticals pass their expiry date, no one can utilize them. 
On the contrary, having too little inventory leads to stock-outs leading to diminished quality of patient care. ${ }^{1}$

The pharmaceutical supply chain involves complex systems that consist of interrelated and interlocking subsystems. Inventory management, as a component, plays a prominent role in the overall performance of the supply system. Improving inventory management practices realizes significant advancement in the supply system. ${ }^{2}$

The continuous supply of pharmaceutical commodities can be guaranteed only through an appropriate inventory management practice. Little mistakes in stock administration can rapidly lead to disarray, expanded turnaround times, unnecessary costs that endanger patient health. ${ }^{3}$ With a well-managed inventory, uncertainties in demand order cycle become less likely. The best management of pharmaceutical inventory involves monitoring expiration dates, inventory levels, unexplained losses, and storage conditions. ${ }^{4}$

Over the past decades, the scientific world introduced several pathbreaking advances that brought medicines into existence to defeat many infectious diseases. Despite this, HIV (Human Immuno Deficiency Virus), tuberculosis (TB), and malaria are among the leading causes of death in sub-Saharan Africa. Failing to appropriately manage those powerful medicines will continue to result in preventable deaths and staggering costs. Besides those infectious diseases, maternal and child mortality is an additional headache to the region. ${ }^{5,6}$

According to 2016's report, the global fund had spent US $\$ 32.6$ billion to support programs for HIV, TB, and malaria. Such a considerable amount of spending needs appropriate management to reduce the burden of those diseases and the associated wastage. ${ }^{7}$ Contrasting to this, a study conducted in Addis Ababa, Ethiopia reported some storage inefficiencies like misarrangement of products, lack of cleanliness of the stores, and inadequacy of storage space. ${ }^{8}$ A similar study conducted in Eastern Ethiopia also reported space deficit, product misarrangement, and shortage of shelves. ${ }^{9}$

Inventory management aims at ensuring continuous supply at a lower possible cost. A study conducted in Ethiopia, however, showed that the average length of stock out days for essential drugs during the past 12 months before the study was 40.6 days. ${ }^{10}$ The consequence of such stock out is far more than mere stock out resulting in lost revenue. Such a shortage of medicines may compromise health care delivery resulting in a detrimental public health impact. ${ }^{11}$
Studying the inventory management practice at the upstream supply system is an anchor to systematically identify and solve inventory management problems of the country as a whole. Despite this, limited information is available in this regard. Majority of previous studies so far evaluated inventory management practices at service delivery points like hospitals and health centers. The focus of this research, therefore, was to understand the inventory management practice of program commodities at the upper supply chain unit of Ethiopia, EPSA. To achieve the objective of the study, metrics like order fill rate, wastage rate, frequency of emergency order, acceptable storage condition met, and the stock-out rates were measured. The challenges of inventory management were also among the examined once. As a study executed at the core organization responsible for pharmaceuticals supply throughout Ethiopia, it has a great significance in implying the need for system improvement. Besides, the finding serves as baseline evidence for future works.

\section{Methods}

\section{Study Setting}

The study was conducted at the Ethiopian Pharmaceutical Supply Agency (EPSA) main branch. EPSA is a governmental organization mandated to avail affordable and quality pharmaceuticals sustainably to the public. Currently, there are 19 hubs throughout the country which are located based on geographic accessibility to health facilities. The central EPSA is responsible for resupplying the 19 branch hubs. Whereas, branch hubs supply health facilities. Every two months, branch hubs place an order to the central EPSA. The agency manages both program (donated and free) and purchased pharmaceuticals. In 2009, the agency introduced an automated Health Commodity Management Information System (HCMIS). The HCMIS automatically orders, manages inventory, and produces a variety of commodity reports. The central branch has ten warehouses located in different sub-cities in Addis Ababa. ${ }^{12}$

\section{Study Design and Period}

A descriptive cross-sectional study complemented with a qualitative method was conducted from February 21April 20/2019.

\section{Source Population}

All commodities managed by EPSA, all health professionals working in EPSA, and logistic documents used to control program commodities were the source population. 


\section{Study Population}

All program commodities, selected key-informants working in central EPSA, and selected logistic management tools like Report and Requisition formats (RRFs), purchase orders, and HCMIS were reviewed to collect the necessary data.

\section{Inclusion and Exclusion Criteria}

Having plenty of experience in the logistics management of program commodities was the inclusion criteria. We excluded staff of the agency who were not present at the time of data collection and incomplete documents.

\section{Sample Size Determination and Sampling Procedure}

The study included all program commodities (17 HIV,31 $\mathrm{TB}, 12 \mathrm{MCH}$, and 10 malaria) managed by EPSA. ${ }^{13}$ The sample size determination of RRF took the schedule of sending RRFs into consideration. EPSA hubs send their RRFs every two months to the central branch. Each branch hub sends six RRFs in a year. The 19 branch hubs located in different areas of Ethiopia, should send a total of 114 RRFs per year. However, one branch hub did not start program pharmaceutical services at the time of data collection. Therefore, we evaluated 108 RRFs (six RRFs from the eighteen branch hubs) to assess the resupply ability of the agency. Concerning purchase order documents, the study included purchase documents (39 purchase orders) of all purchases. To evaluate the storage condition, all central EPSA warehouses were visited. Seventeen key informants selected for an in-depth interview. Participants were selected by purposive sampling according to their experience in the area. The sample size of the informants was determined based on theoretical saturation. Sampling stopped when new ideas cease to emerge.

\section{Data Collection Procedure}

We used a semi-structured questionnaire and checklist developed by the United States Agency for International Development (USAID) to collect quantitative data. The storage conditions of the warehouses were checked through physical observation using standard 17 criteria adapted from the LIAT tool. ${ }^{14}$ RRFs of one-year duration reviewed to evaluate the order fill rate of the agency. HCMIS records of the past one-year assessed retrospectively to collect data on wastage rate and stock out. Purchase order documents were evaluated to measure the emergency order level.
Key-informants were interviewed with flexible probing questions to identify challenges in inventory management. Logistic System Assessment Tool (LSAT) developed by USAID was adapted to the local situations and used as an interview guide. ${ }^{15}$ We obtained verbal informed consent from the participants. Then the key informants were interviewed face to face. Each interview, on average, lasted for 20 minutes. The interviews were conducted by the principal investigator to maintain consistency. The records were listened several times and transcribed from the voice recorder.

\section{Measurements}

The following measurements were used in the current study. ${ }^{16}$

1. Order Fill Rate: it measures the percentage of all customer orders placed to a distribution source over a period that is filled correctly in terms of items and quantities of those item.

Order fill rate $=\left(\frac{\text { Number of orders filled correctly }}{\text { Total number of orders placed }}\right)$

$$
* 100
$$

2. Percentage of stock wasted due to expiration and damage over a period of one year: it measures the percentage of stock for an item that is unusable because of expiry and damage during one year to the total quantity of that item received during a year plus quantity of those items found during the beginning period of the year.

$\%$ of stock wasted due to expiry $\&$ damage $=\left(\begin{array}{c}\text { unusable stock of an } \\ \begin{array}{c}\text { Begining during lyear } \\ \text { of the item during 1year }\end{array}\end{array}\right) * 100$

3. Percentage of emergency purchase: it measures the percentage of emergency orders out of all purchase orders or contracts placed during a defined period. This was determined using the following formula:

$$
\begin{aligned}
& \text { Percentage of emergency purchase } \\
& =\left(\begin{array}{l}
\text { Number of emergency } \\
\text { orderes placed } \\
\text { Total number of purchases }
\end{array}\right) * 100
\end{aligned}
$$

4. Percentage of warehouses that maintain acceptable storage conditions: measures the percentage of 
warehouses that meet acceptable or desired storage conditions. This was determined using the following formula:

$$
\begin{aligned}
& \% \text { of warehouses that met critera } \\
& =\left(\begin{array}{c}
\text { No.of warehouses that } \\
\text { fulfilled critera } \\
\begin{array}{c}
\text { Total no. of warehouses } \\
\text { visited }
\end{array}
\end{array}\right) * 100
\end{aligned}
$$

5. Value of unusable stock as percentage of total inventory value: it measures the value of a stock that was unusable due to damage and expiry as a percentage of total items purchased during a defined period

Value of unusable stock as \% of total

inventory value $=\left(\frac{\text { value of unusable stock }}{\text { total inventory value }}\right) * 100$

\section{Data Processing and Analysis}

The quantitative data were cleared, coded and entered into the statistical package for social sciences version 23 (SPSS) for analysis. Descriptive statistics computed and results were presented using texts, tables, and charts. Qualitative data were analyzed using a thematic content analysis approach. Data were coded in a word document and then the codes were used to search for themes. Finally, the findings were triangulated with quantitative results.

\section{Operational Definitions}

Program commodities: refers to pharmaceuticals used to manage HIV/AIDS, TB, MCH and malaria cases.

Wasted items: - refers to unusable items due to expiry and damage

\section{Results}

\section{EPSA's Order Fill Rate}

EPSA fulfilled only 16 (14.81\%) of the orders above $80 \%$ from 108 total orders placed by branch hubs. The Mean order fill rate was $52.9 \%$ (Table 1).

\section{Emergency Orders of Program Commodities}

The agency purchased selected program commodities 14 times in the past one year. Three of the orders were emergencies. The rest of the others were ordinary purchases. However, the total purchase orders evaluated are 39 in number. Since 11 of the ordinary purchases had 36 orders (one purchase divided into many delivery schedules), the total number of purchase orders evaluated was 39 in number.

Out of seventy program commodities included in the study, the agency purchased 17 (24.29\%) with emergency orders at least once in the past year. A higher frequency of emergency order record was for levonorgestrel (D-Norgestrel) - 0.75mg - Tablet (Table 2).

\section{Wastage of Program Commodities}

The monetary value of the commodities was calculated based on the current unit price obtained from the EPSA price list. Accordingly, from the total inventory value (US $\$ 111,032,284.25)$ of program commodities, US $\$ 2,283,640.662$, or $2.1 \%$ was lost in one year. (Table 3 ). The highest recorded wastage $(13.1 \%$ of their inventory value) was that of anti-malarial medications. The most wasted product was artemether+ lumefantrine $(20 \mathrm{mg}$ $+120 \mathrm{mg}$ ) tablet $(6 \times 3)$ : which was $29.91 \%$ of its total inventory value. (Table 3, Supplementary Table 1/2/3/4)

\section{Stock Out of Program Commodities}

Out of 70 medicines assessed, 37 items had faced stock out in the past year with the highest duration (260 days) for anti-TB commodities. In the agency, program commodities stock out on average for 8.5 days (Table 4). IUCD (36 days), 3TC-30mg + AZT-60 mg (35 days), artemether/lumefantrine (26 days), and moxifloxacin (47 days) were the most stocked out items from each program. The highest frequency of stockout ( 2 times in a year) record was that of abacavir and levonorgestrel (Supplementary Table 1/2/3/4)

Table I Central EPSA Order Fill Rate of Program Commodities April 2019

\begin{tabular}{|l|l|l|l|l|l|l|}
\hline & $\begin{array}{l}\text { No. of Orders } \\
\text { Evaluated }\end{array}$ & Mean & $\begin{array}{l}\text { Standard } \\
\text { Deviation }\end{array}$ & Minimum & Maximum & $\begin{array}{l}\text { Orders with Acceptable (>80\%) } \\
\text { Fill Rate N (\%) }\end{array}$ \\
\hline $\begin{array}{l}\text { Order fill rate of } \\
\text { central EPSA }\end{array}$ & 108 & 52.9 & 22.74 & 9 & 91 & $16(14.81 \%)$ \\
\hline
\end{tabular}


Table 2 Central EPSA Emergency Order of Program Commodities, April 2019

\begin{tabular}{|c|c|c|}
\hline S. No & Products Purchased by Emergency Orders & Frequency of Emergency Purchase \\
\hline 1 & $3 T C+E F V+$ TDF $(300+600+300) \mathrm{mg} \mathrm{tab}$ & I \\
\hline 2 & $3 T C+N V P+A Z T(150+200+300) m g$ tab & I \\
\hline 3 & $3 T C+N V P+A Z T(30+50+60) \mathrm{mg}$ tab & I \\
\hline 4 & $3 \mathrm{TC}++\mathrm{AZT}(150+300) \mathrm{mg}$ tab & 1 \\
\hline 5 & NVP $10 \mathrm{mg} / \mathrm{mL}, 20 \mathrm{~mL}$ oral suspension & I \\
\hline 6 & Artemether + Lumefantrine $-(20 \mathrm{mg}+120 \mathrm{mg})$ Tablet $(6 \times \mathrm{I})$ & 1 \\
\hline 7 & Artemether + lumefantrine $(20+120) \mathrm{mg} 6 \times 2$ tablet & 1 \\
\hline 8 & Artemether + Lumefantrine $-(20 \mathrm{mg}+120 \mathrm{mg})$ Tablet $(6 \times 3)$ & 1 \\
\hline 9 & Artemether + Lumefantrine $-(20 \mathrm{mg}+120 \mathrm{mg})$ Tablet $(6 \times 4)$ & 1 \\
\hline 10 & Artesunate $-60 \mathrm{mg}-$ Vial - Injection & I \\
\hline II & Chloroquine Phosphate - 50mg - syrup & 1 \\
\hline 12 & IUCD (Intrauterine Contraceptive Device) - Long acting & 1 \\
\hline 13 & Levonorgestrel - $75 \mathrm{mg} / \mathrm{rod}$ of 2 rods - implant rods (Sub dermal) with sterile insertion trocar & I \\
\hline 14 & Levonorgestrel (D-Norgestrel) - $0.75 \mathrm{mg}-$ Tablet & 2 \\
\hline 15 & Amino salicylic Acid Delayed - Release granules,4gms - Solution & I \\
\hline 16 & Prothionamide- $250 \mathrm{mg}$-Tab & I \\
\hline 17 & Pyrazinamide- 400g-tab & I \\
\hline
\end{tabular}

Table 3 Wastage Rate of Program Commodities, Central EPSA, April 2019

\begin{tabular}{|l|l|l|l|}
\hline $\begin{array}{l}\text { Type of Program } \\
\text { Commodity }\end{array}$ & $\begin{array}{l}\text { Total Inventory Value in ETB } \\
\text { (\$US**) }\end{array}$ & $\begin{array}{l}\text { Value of Inventory Wasted in ETB* } \\
\text { (\$US) }\end{array}$ & $\begin{array}{l}\text { \% Wastage } \\
\text { Rate }\end{array}$ \\
\hline HIV & $1,397,865,125(39,752,28 I)$ & $7,252,652(206,249.8)$ & 0.52 \\
Anti-TB & $3,195,615(90,876.4)$ & $13,117,931.08(373,045.8)$ & 4.1 \\
MCH & $1,811,512,755(51,515,531.5)$ & $19,693,544(560,042.1)$ & 1.09 \\
Anti-Malaria & $292,457,627(8,3 \mid 6,866.7)$ & $38,536,49 I(I, 095,895)$ & 13.18 \\
Total & $3,821,397,092(108,672,324.6)$ & $78,600,618.75(2,235,232.76)$ & 2.1 \\
\hline
\end{tabular}

Notes: *ETB=Ethiopian birr. $*$ * $\$$ U $=$ United States dollar.

\section{Storage Conditions of Central EPSA Warehouses}

From the ten warehouses assessed, only $6(60 \%)$ warehouses met acceptable storage conditions (fulfilled $80 \%$ of the criteria or more) (Figure 1).

\section{Challenges for Inventory Management of Program Commodities}

The analysis of the in-depth interviews identified three themes related to warehouse adequacy, demand information, and capacity building.

\section{Warehouse Adequacy-Related Challenges}

An adequate and well-managed warehouse ensures speedy and complete service whenever customers place their orders. Besides this, unlike other ordinary goods, pharmaceutical warehouses require special care for maintaining the quality of products. Moreover, maintaining proper storage conditions reduces damage and simplifies tracing and tracking. If that is so, officers can identify nearly expiring and lasting commodities without difficulty. It's also easier to identify seasonally consumed products. In this study, however, the informants reported that some of the warehouses do not possess adequate facilities to manage large inventory. In some of them, storage spaces were insufficient. Warehouse managers store the products in different warehouses where vacant space is available. Some warehouses are old designs and not suitable for storage. Most of the warehouses have no appropriate dock. Some of them did not have the required storage equipment. One of the store managers explained the problems as follows,

Some warehouses have no racks and other necessary handling equipment. As a result, we face difficulty to zone the warehouses implementing FEFO (First Expiry First Out). Some of the products are stored on pallets making the physical tracing difficult. Due to this, 
Table 4 Stock Out of Program Commodities, Central EPSA, April 2019

\begin{tabular}{|l|l|l|l|l|}
\hline $\begin{array}{l}\text { Type of } \\
\text { Medicine }\end{array}$ & $\begin{array}{l}\text { Total Number of Items } \\
\text { Assessed }\end{array}$ & $\begin{array}{l}\text { Number of Items Stocked } \\
\text { Out }\end{array}$ & $\begin{array}{l}\text { Days of Stock } \\
\text { Out }\end{array}$ & $\begin{array}{l}\text { Average Days of Stock Out per } \\
\text { Item }\end{array}$ \\
\hline HIV & 17 & 15 & 207 & 12.17 \\
MCH & 12 & 5 & 70 & 5.83 \\
Anti-Malarial & 10 & 6 & 58 & 5.8 \\
Anti_TB & 31 & 11 & 260 & 8.4 \\
Total & 70 & 37 & 595 & 8.5 \\
\hline
\end{tabular}

sometimes, though there is sufficient stock, products are considered as stock out. Consequently, they expire.

\section{Demand Information-Related Problems}

Estimating future demand is one of the most critical activities an organization involved in the supply chain can undertake. Precise demand information from customers on different levels is the primary decision-making factor. If demand data arrive incomplete, inaccurate, or delayed, the order management relies on assumptions and experience. Improvements in the quality of demand data can produce a ripple outcome. Significant reduction of inventory buffers, obsolete products, and storage space deficit are among the mentioned outcomes. In turn, these improvements lead to higher-order fill rates. In general, effective demand planning allows an institution to be more proactive and puts it in a better position to avoid stock outs or excess stocks. Despite this, the interviewees pointed up a lack of clear and accurate demand reports. As a result, the agency usually faces an imbalance between demand and supply.

One of the interviewees explained the problem as follows:

"The major problem we encounter in managing our inventory is unclear and inaccurate demand reports from our customers. Sometimes this obliges the agency to store excess/small amounts. At last, this ends up with stock out or expiry."

Capacity Building- Related Challenge:

Building capacity of staff is a key to the success of any organization. The lack of qualified individuals is a threat that results in ineffective role performance. In this respect, several organizations overlook supportive staff like drivers. Adequately trained staff is not only more capable

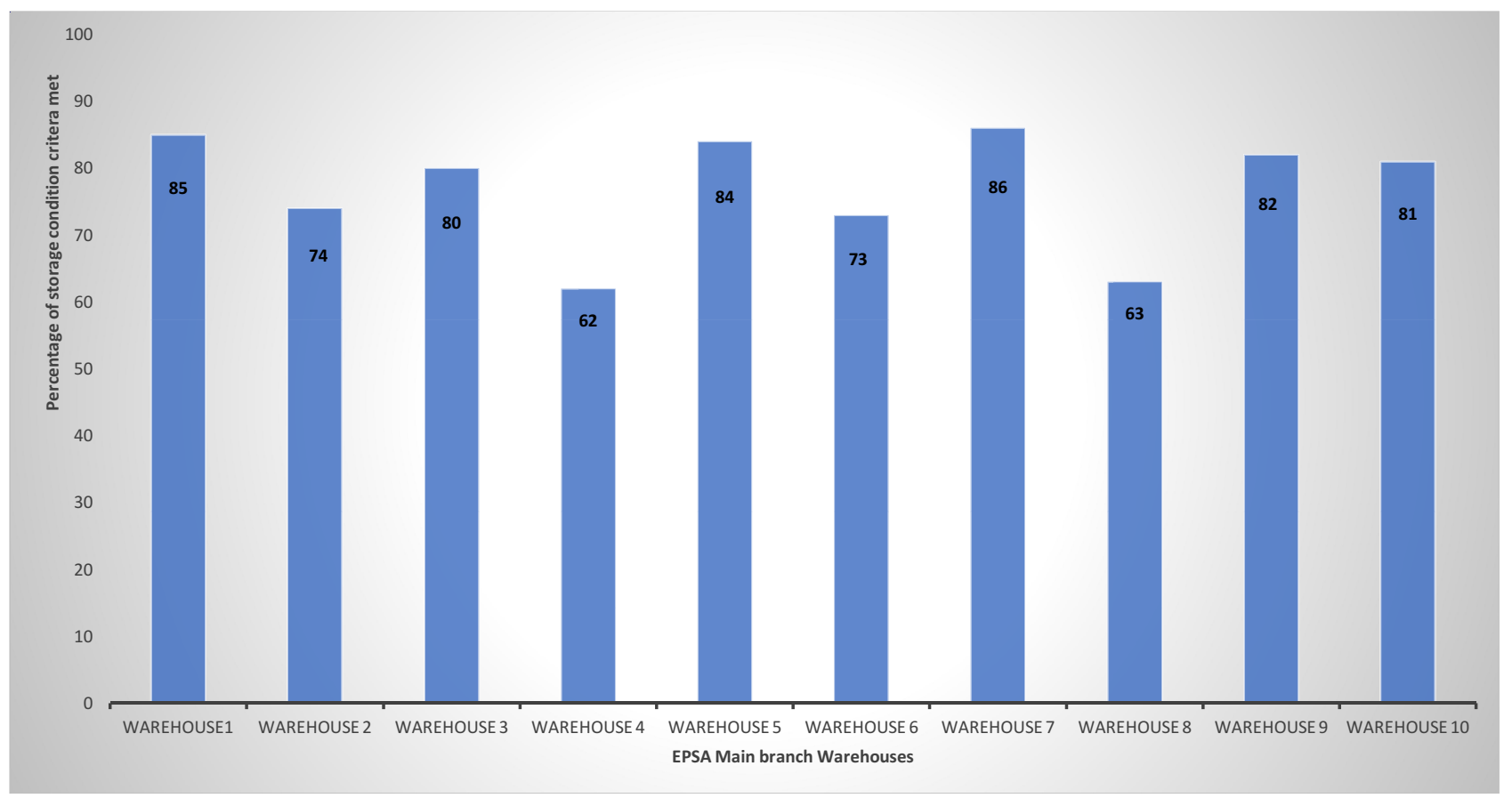

Figure I Percentage of acceptable storage condition met by EPSA warehouses, April 2019. 
but less likely to cause costly mistakes. A well-trained employee is better accustomed to the particulars of their job and will require less supervision. Aside from this, interviewees mentioned a lack of sufficient training on pharmaceutical handling among drivers and loadingunloading professionals. As to the informants, providing adequate orientation to those supportive staff is a possible solution for this. One of the EPSA inventory officers highlighted the problem as follows;

"drivers sometimes transport other non-pharmaceutical products together with pharmaceuticals exposing products to physical damage. Furthermore, some of the individuals executing loading and unloading have inadequate awareness of pharmaceutical handling. Owing to this, disarrangement and damage to the products occur. "

\section{Discussion}

An effective inventory management system fully satisfies customer orders in the correct quantities and type. In Ethiopia, the fulfillment of orders of at least $80 \%$ is acceptable. $^{16}$ In the current study, 16 (14.81\%) orders fulfilled above $80 \%$ with a mean order fill rate of $52.9 \%$. The finding is comparable with the Benin national supply chain assessment. ${ }^{17}$ However, it was far below the acceptable Ethiopian standards. Evidence from the key informants showed that because of storage space deficit, store personnel maintains products at any vacant space available. Owing to this, tracking and tracing of products became difficult leading to lower-order fill rates. The finding implies that there is a need for extensive reform in the order processing system of the agency. Effortful evaluation is needed to identify potential areas of intervention.

The finding revealed that from 14 purchases of program commodities, three $(21.43 \%)$ emergency orders were issued for 17 items. As a result of this, the possibility of stock out and supply interruption was higher in the agency. Usually, emergency orders are needed to cope with product stock out. However, emergency orders are ruinously expensive as compared to regular once. ${ }^{1}$ The finding suggests that EPSA has incurred additional costs that could be prevented by adequate inventory management practices. As evidenced by the in-depth interview, the inefficient demand planning and forecasting emanating from inadequate demand information contributed a lot to the occurrence of emergency orders.

A resilient inventory management system results in a wellmaintained stock level and lesser wastages. Promisingly, the wastage rate of program commodities in the agency was $2.1 \%$.
The finding is almost near to the target wastage rate of the Ethiopian health sector development program. ${ }^{18}$ Though the aggregate wastage rate was acceptable, individual evaluation of the wastage rate of program commodities shows significant wastage. For example, the wastage rate of malaria $(13.18 \%)$ and TB commodities $(4.1 \%)$ were more than a hundred times the acceptable standard. The key informants' interview revealed that failing to apply FFEO and damages due to mishandling during delivery and loading-unloading might have contributed to the wastage.

The availability of drugs largely influences the quality of healthcare and patient satisfaction. Despite this, in the current study, program commodities were out of stock on average for 8.5 days with a higher duration for malaria commodities. The finding is comparable with a study conducted in Kenya which reported significant malaria commodity stock out. ${ }^{19}$ Regarding $\mathrm{MCH}$ products, out of $12 \mathrm{MCH}$ products assessed, $5(41.7 \%)$ were out of stock on average for 5.83 days. The finding is in agreement with the study conducted in Kenya, where $40 \%$ of $\mathrm{MCH}$ priority commodities were out of stock. $^{20}$ Concerning TB commodities, 11 (35.48\%) were out of stock on average for 8.39 days. This result is better than the audit report of global fund grants in the Republic of Niger, where TB drugs were out of stock for several months. ${ }^{21}$ The discrepancy might be associated with differences in disease demography between the two countries. Non-availability of such essential program commodities at the upstream supply chain system means a lot. It potentially results in service interruption at the downstream supply chain system. Besides, stock out of such vital items threatens the survival of many.

According to the Ethiopian standard, warehouses should fulfill at least $80 \%$ of the storage condition criteria. ${ }^{16}$ In the present study, however, only six warehouses met acceptable storage conditions. The qualitative result also revealed challenges like insufficient storage spaces, old warehouse designs, and a shortage of warehouse equipment. According to WHO, maintaining proper storage conditions for health commodities is vital to ensure their quality and accordingly serve customers. The design of large storage buildings should take into account the storage conditions required for different products. Unlike other ordinary goods, storage conditions can easily damage health commodities. Recommended storage conditions should be maintained to maintain product quality. ${ }^{22}$ Thus, in the agency, there is a critical need for regular evaluation of the adequacy of storage facilities, layout, and stock arrangement. 


\section{Conclusion}

The wastage rate of the agency was acceptable. However, some inventory management practices imply the need for improvement. The occurrence of emergency orders, lesser order fill rate, significant stock out of products, and inadequate storage conditions were the inventory management inefficiency manifestations. Lack of adequate demand information, warehouse premises shortcomings, and capacity building gaps were the challenges behind the inefficiencies.

\section{Abbreviations}

3TC, Lamivudine; AIDS, Acquired immune deficiency syndrome; ART, Antiretroviral treatment; AZT, Zidovudine; EPSA, Ethiopian Pharmaceuticals Supply Agency; HCMIS, Health commodity management information system; HIV, Human immune deficiency virus, LIAT, Logistic indicator Assessment Tool; LMIS, logistics management information system; LSAT, Logistic System Assessment Tool; MCH, Maternal and child health; RRF, Reporting and resupply form; SPSS, Statistical Package for Social Sciences; TB, Tuberculosis; US, United States; USAID, Unites States Aid for International Development; WHO, world health organizations.

\section{Data Sharing Statement}

The data sets generated during and/or analyzed during the current study are available from the corresponding author on reasonable request.

\section{Ethics Approval and Consent to Participate}

The study was conducted according to the criteria set by the declaration of Helsinki. An informed oral consent received from the respondents to ascertain willingness of participation and this method has got approval by Institutional Review Board of Jimma University.

Ethical clearance has been received from the Institutional Review Board of Jimma University (IRB) (Ref.no.IHRPGD/607/2019) on 17 April 2019.Then letters of permission were received from the Federal Ministry of Health \&EPSA. Throughout the data collection, we preserved the professional and social principles and didn't indicate participants in the data collection tools.

\section{Acknowledgments}

We thank Jimma University for facilitating the study. We extend our heartfelt gratitude to our data collectors, study participants, and all staffs of central Ethiopian Pharmaceutical Supply Agency for their kind cooperation.

\section{Funding}

Jimma University had covered stationery and data collection costs.

\section{Disclosure}

The authors report no conflicts of interest for this work.

\section{References}

1. Management science for health. MDS-3: Managing Access to Medicines and Health Technologies; 2012.

2. Kritchanchai D, Meesamut W. Developing inventory management in hospital. Int J Supply Chain Manag. 2015;4(2):11-19.

3. USAID/DELIVER project. Guidelines for managing the laboratory supply chain: version 2. Arlington, Va: USAID | DELIVER PROJECT, Task Order 1 [Internet]; 2008:1-86. Available from: https://www.jsi.com/JSIInternet/Inc/Common/_download_pub.cfm? id=11109\&lid=3. Accessed May 12, 2019.

4. Chen Y, Chang H. Improve the management of pharmaceutical inventory by using an IoT based information system. Int J Soc Sci Humanit. 2017;7(8):569-573.

5. Global fund. Ending Aids, Tb and Malaria as Epidemics a Smart; 2019.

6. Fowkes FJI, Draper BL, Hellard M, Stoové M. Achieving development goals for HIV, tuberculosis and malaria in sub-Saharan Africa through integrated antenatal care: barriers and challenges. BMC Med. 2016;14(1):1-10. doi:10.1186/s12916-016-0753-9

7. Global Fund. The Office of the Inspector General; 2017:1-110

8. Berhanemeskel E, Beedemariam G, Fenta TG. HIV/AIDS related commodities supply chain management in public health facilities of Addis Ababa, Ethiopia: A cross-sectional survey. $J$ Pharm Policy Pract. 2016;9(1):1-10. doi:10.1186/s40545-016-0060-z

9. Kassie GM, Mammo S. Assessment of pharmaceutical store management in Woreda Health Offices of West Hararghe Zone, Ethiopia. Int Res J Pharm. 2014;5(8):642-645. doi:10.7897/2230-8407.0508131

10. Kefale AT, Shebo HH. Availability of essential medicines and pharmaceutical inventory management practice at health centers of Adama town, Ethiopia. BMC Health Serv Res. 2019;19(1):1-7. doi:10.1186/s12913-019-4087-0

11. Toba S, Tomasini M, Yang YH. Supply chain management in hospital: a case study. Calif J Oper Manag. 2008;6(1):49-55.

12. About us - Ethiopian Pharmaceuticals Supply Agency - EPSA [Internet]. [cited June 24, 2020]. Available from: https://epsa.gov.et/ about-us-2/. Accessed September 10, 2020.

13. Pharmaceuticals Fund and Supply Agency. Pharmaceuticals procurement list; April 2018:1-80. Available from: https://epsa.gov.et/featured-services/procurement-list/. Accessed December 12, 2018.

14. USAID. Logistics Indicators Assessment Tool (LIAT); 2005.

15. USAID | DELIVER PROJECT Task Order 1. Logistics System Assessment Tool (LSAT). Arlington, Va: USAID | DELIVER PROJECT, Task Order 1 $1 \mathrm{r} ; 2009$.

16. EPSA. The Ethiopian pharmaceuticals supply chain management system monitering and evaluation training participant manual; May 2017.

17. Nfor E, Maxim L, Gbaguidi A, Levenger M, Conesa S Benin National Supply Chain Assessment. Submitted to the US Agency for International Development by the Systems for Improved Access to Pharmaceuticals and Services (SIAPS) Program. Arlington, VA: Management Sciences for Health; March 2016:4-84. Available from: http://siapsprogram.org/wp-content/uploads/2018/05/16-031-BeninNSCA-Technical-Report.final_.pdf. Accessed May 23, 2019. 
18. Federal Democratic Republic of Ethiopia Ministry of Health. Health sector development programme IV plan 2010-2015; October 2010:1-141.

19. Tren R, Hess K, Bate R. Drug procurement, the Global Fund and misguided competition policies. Malar J. 2009;8(1). doi:10.1186/ 1475-2875-8-305

20. Aronovich D, Kinzett S. Assessment of the Health Commodity Supply Chains and the Role of KEMSA. Arlingington: DELLIVER/John Snow Inc.; 2001.
21. Global Fund. Global Fund Grants In The People's Republic of Niger; September 2017:1-19.

22. John Snow, Inc./DELIVER in collaboration with the World Health Organization. Guidelines for the Storage of Essential Medicines and Other Health Commodities. 2003:114

\section{Publish your work in this journal}

Integrated Pharmacy Research and Practice is an international, peerreviewed, open access, online journal, publishing original research, reports, reviews and commentaries on all areas of academic and professional pharmacy practice. This journal aims to represent the academic output of pharmacists and pharmacy practice with particular focus on integrated care. All papers are carefully peer reviewed to ensure the highest standards as well as ensuring that we are informing and stimulating pharmaceutical professionals. The manuscript management system is completely online and includes a very quick and fair peer-review system, which is all easy to use. Visit $\mathrm{http}: / / \mathrm{www}$.dovepress.com/testimonials.php to read real quotes from published authors. 